\title{
Streptococcus pyogenes Escapes Killing from Extracellular Histones through Plasminogen Binding and Activation by Streptokinase
}

\author{
Ramona Nitzsche Juliane Köhler Bernd Kreikemeyer Sonja Oehmcke-Hecht \\ University Medicine, Institute of Medical Microbiology, Virology and Hygiene, Rostock University, Rostock, Germany
}

\author{
Key Words \\ Streptococcus pyogenes $\cdot$ Streptokinase $\cdot$ Extracellular \\ histones
}

\begin{abstract}
Histones are small basic proteins and highly conserved among eukaryotes. Their main function is binding, packaging and organizing of DNA in the nucleus, but extracellular histones are also potent antimicrobial proteins. Here we found that Streptococcus pyogenes - an important human pathogen - protects itself from histone-killing by the acquisition of plasminogen. Plasminogen, bound to the streptococcal surface, efficiently prevents histone-mediated killing. Moreover, the streptokinase/plasminogen complex degrades all classes of histones and abrogates their antibacterial and hemolytic effects. This novel streptokinase-mediated virulence mechanism may contribute to the escape of S. pyogenes from the human innate immune system.
\end{abstract}

(c) 2016 S. Karger AG, Basel

\section{Introduction}

The obligate human pathogen Streptococcus pyogenes, also referred to as group A streptococcus (GAS), causes superficial infections of both the skin and mucous membranes, e.g. impetigo or pharyngitis, as well as invasive live-threatening diseases, like sepsis and necrotizing fasciitis [1]. In all these cases, the bacterium encounters a manifold repertoire of host defense mechanisms, antimicrobial peptides among them. When it was discovered that histones are released into the extracellular space, their role in infection and disease was revisited. Acting as antimicrobials and major mediators in the pathogenicity of sepsis, they are now thought to complement the innate immune system [2]. Histones are small basic proteins, classified into 5 subtypes ( $\mathrm{H} 1, \mathrm{H} 2 \mathrm{~A}, \mathrm{H} 2 \mathrm{~B}, \mathrm{H} 3$ and $\mathrm{H} 4)$, and are highly conserved among eukaryotes. Due to their cationic properties, they bind to DNA in the nucleus, and are involved in chromatin organization, replication and gene transcription regulation [3]. Moreover, extracellular histones have been found to kill various Gram-positive and Gram-negative bacteria as well as certain fungi and parasites. Of note, histones are powerful antimicrobials, and it has been shown that one mole of histones can kill approximately 100 -fold more bacteria than other antimicrobials, such as $\beta$-defensins [2]. Although this was known as early as 1958 [4], the potential of histones as antimicrobial agents in the early events of human innate immunity was neglected for decades. But since neutrophil extracellular traps (NETs) were discovered in 2004 [5], a growing body of evidence suggest that histones may play a crucial role in immune defense. NETs are composed of chromatin and granular proteins that are released into the extracellular space by stimulated neutro-

\section{KARGER}

E-Mail karger@karger.com

www.karger.com/jin
C 2016 S. Karger AG, Basel

$1662-811 \mathrm{X} / 16 / 0086-0589 \$ 39.50 / 0$
Dr. Sonja Oehmcke-Hecht

University Medicine, Institute of Medical Microbiology, Virology and Hygiene Rostock University

Schillingallee 70, DE-18055 Rostock (Germany)

E-Mail Sonja.Oehmcke-Hecht@ uni-rostock.de 
phils. These structures accumulate histones and other antimicrobial peptides, and are found at sites of infection as well as in the bloodstream of animals with septic shock [6], where they trap and kill microbes (review [7]). However, extracellular histones are not only present in NETs but have also been detected in the secreted cocktail from human sebocytes that helps to protect against skin pathogens [8].

Inducing the release of antimicrobial peptides and histones on the one hand, S. pyogenes has also developed many strategies to counteract this part of the immune response $[9,10]$. Apart from expressing degrading enzymes, bacteria can also achieve the elimination of harmful immunopeptides by exploiting host proteases. In this context, $S$. pyogenes is known to utilize the human plasminogen/plasmin system. The serine protease plasmin circulates in human blood and plasma as inactive precursor that is bound and activated by GAS. Immobilized via plasminogen receptors on the streptococcal surface, plasminogen is prone to activation by its physiological activators, tissue plasminogen activator (tPA) or urokinase plasminogen activator ( $\mathrm{uPA})$. The conversion to the active enzyme form is accelerated by the secreted streptococcal virulence factor streptokinase $[11,12]$. Further on, streptokinase is assembled on the GAS surface in a trimolecular complex containing streptokinase, fibrinogen and plasminogen [13]. Thereby, plasmin activity is generated on the streptococcal surface and involved in invasive spread by degrading fibrin clots, components of the extracellular matrix and antimicrobial peptides $[11,14]$. It has been shown that plasmin cleaves histones in vitro [15], and it is assumed that histones operate by disintegrating or penetrating the bacterial membrane $[16,17]$. We therefore speculated that plasminogen acquisition at the streptococcal surface might serve as a survival strategy of GAS in an environment with high local concentrations of extracellular histones. To address this question, we examined the ability of purified histones from calf thymus $(\mathrm{CTH})$ as well as recombinant single histones to inhibit the growth of a GAS M49 serotype strain with degradation before or after by plasmin or streptokinase-activated plasminogen.

\section{Material and Methods}

\section{Bacterial Strains and Culture Conditions}

The S. pyogenes serotype M49 wild-type (WT) strain 591 was received from R. Lütticken (Aachen, Germany). An isogenic-deficient mutant lacking streptokinase $(\Delta s k a)$ was previously generated by insertional inactivation of the ska gene with an antibiotic resistance cassette for spectinomycin [18]. Bacteria were cultured in Todd-Hewitt broth supplemented with yeast extract (THY) at $37^{\circ} \mathrm{C}$ in a $5 \% \mathrm{CO}_{2}$ and $20 \% \mathrm{O}_{2}$ atmosphere. When necessary, spectinomycin was added to a final concentration of $60 \mu \mathrm{g} / \mathrm{ml}$.

\section{Materials}

Lyophilized human plasminogen and plasmin were purchased from Enzyme Research Laboratories (Swansea, UK) and SigmaAldrich (Steinheim, Germany), respectively, and dissolved in water or buffer to $1 \mathrm{mg} / \mathrm{ml}$. Purified streptokinase from beta-hemolytic streptococci was acquired from Sigma-Aldrich and concentrated to 10 units per microliter of water. Human uPA and tPA were purchased from Haemochrom Diagnostica (Essen, Germany).

A mix of all histone subtypes from calf thymus as well as recombinant human histones $\mathrm{H} 2 \mathrm{~A}, \mathrm{H} 2 \mathrm{~B}$ and $\mathrm{H} 4$, were purchased from Sigma-Aldrich. Purified histone $\mathrm{H} 1$ and $\mathrm{H} 3$ derived from calf thymus were obtained from Calbiochem (Billerica, Mass., USA) and Roche Diagnostics (Mannheim, Germany), respectively. Histones were dissolved in $10 \mathrm{mM}$ Tris buffer ( $\mathrm{pH}$ 7.4) and diluted to appropriate concentrations for each experiment. Human native nucleosomes purified from HeLa cell nuclei were purchased from Merck Millipore (Darmstadt, Germany). Fresh frozen citrated plasma samples from healthy individuals were obtained from the blood bank at Rostock University Hospital, Rostock. Plasminogen-depleted human citrated plasma was purchased from Haemochrom Diagnostica (Essen, Germany). Plasma was stored at $-80^{\circ} \mathrm{C}$ until use.

\section{Histone or Nucleosome Degradation and SDS-PAGE}

Histone or nucleosome degradation was initiated in $10 \mathrm{mM}$ Tris buffer ( $\mathrm{pH}$ 7.4) by adding $1 \mu \mathrm{g}$ plasminogen and $50 \mathrm{U}$ purified streptokinase, or $1 \mu \mathrm{g}$ plasmin to $100 \mu \mathrm{l}(100 \mu \mathrm{g} / \mathrm{ml})$ histones in a total volume of $106 \mu \mathrm{l}$. Histones exposed to buffer or either plasminogen or streptokinase alone served as negative controls. Nucleosomes $(3.2 \mu \mathrm{g})$ were incubated in Tris buffer, with $0.3 \mu \mathrm{g}$ plasmin or $16.6 \mathrm{U}$ purified streptokinaseand $0.3 \mu \mathrm{g}$ plasminogen at $37^{\circ} \mathrm{C}$. Furthermore, $5 \mu \mathrm{l}$ of $S$. pyogenes M49 overnight cultures in combination with plasminogen were added to histones and histone degradation was examined. If indicated, D-Val-Phe-Lys chloromethyl ketone dihydrochloride at a final concentration of $0.5 \mu \mathrm{g} /$ $\mathrm{ml}$ was used to inhibit free plasmin. In some experiments, $500 \mathrm{ng}$ $\mathrm{uPA}$ or tPA were added. Degradation was allowed for up to $4 \mathrm{~h}$ at $37^{\circ} \mathrm{C}$. Subsequently, sample volumes containing approximately $10 \mu \mathrm{g}$ histones or $3 \mu \mathrm{g}$ nucleosomes were mixed with sample buffer with $2 \%(\mathrm{w} / \mathrm{v})$ and $5 \%(\mathrm{v} / \mathrm{v})$ beta-mercaptoethanol, and subjected to SDS-PAGE. This method was performed as described by Neville [19], using gels with $15 \%$ total acrylamide $3 \%$ bisacrylamide. Before loading, samples were boiled for $5 \mathrm{~min}$.

\section{Bactericidal Assays with M49 WT and $\Delta$ ska Mutant}

Exponentially growing cultures $\left(\mathrm{OD}_{600}=0.3-0.4\right)$ of $S$. pyogenes M49 WT or $\Delta$ ska mutant were washed once with $10 \mathrm{~mm}$ Tris buffer and suspended in 10 volumes of fresh buffer; $60 \mu$ of bacterial suspension was mixed with $60 \mu$ l histone solution of different concentrations. In order to examine the influence of plasminogen, albumin or plasma components, $200 \mu \mathrm{g} / \mathrm{ml}$ plasminogen, $35 \mathrm{mg} /$ $\mathrm{ml}$ albumin or $20 \%$ citrated human plasma (normal or plasminogen-depleted) was added to the bacteria and incubated for $15 \mathrm{~min}$. Unbound plasminogen, albumin or plasma components were re- 
moved by an additional washing step, then histones were added to different concentrations. After incubation for $2 \mathrm{~h}$ at $37^{\circ} \mathrm{C}$, serial dilutions were plated on THY agar. Bacterial counts were determined the next day. All results were related to a nontreated control.

\section{Hemolysis Assay}

$1 \mathrm{ml}$ citrated blood was centrifuged at $2,000 \mathrm{~g}$ and $4{ }^{\circ} \mathrm{C}$ for $10 \mathrm{~min}$; plasma was removed and replaced by $1 \mathrm{ml}$ PBS. The washing step was repeated twice. Histones were diluted in PBS to $100 \mu \mathrm{g} / \mathrm{ml}$ in the presence or absence of plasmin $(1 \mu \mathrm{g})$ in a final volume of $100 \mu \mathrm{l}$. Water and PBS served as a positive and negative control, respectively. Three microliters of washed blood cells $(5 \% \mathrm{v} / \mathrm{v})$ were added to each sample and the samples were incubated for $60 \mathrm{~min}$ at $37^{\circ} \mathrm{C}$ on rotation. After incubation, samples were centrifuged at 2,000 $\mathrm{g}$ and room temperature for $10 \mathrm{~min}$, and the supernatants were transferred to microtiter plates. Absorbance of hemoglobin was measured at $540 \mathrm{~nm}$ and histone-induced hemolysis was expressed as a percentage of water-induced hemolysis.

\section{Scanning Electronic Microscopy}

Bactericidal assays were performed as described above in 10fold volumes of $0.9 \%(\mathrm{v} / \mathrm{v})$ saline solution. Histones were used at a final concentration of $0.5 \mu \mathrm{g} / \mathrm{ml}$; plasminogen was added to $200 \mu \mathrm{g} / \mathrm{ml}$. Bacterial pellets were washed, suspended in $0.1 \mathrm{M}$ sodium phosphate buffer ( $\mathrm{pH} 7.2$ ), and completely transferred to lysine-coated plastic coverslips. Material was fixed in $2.5 \%(\mathrm{v} / \mathrm{v})$ glutaraldehyde in sodium phosphate buffer for at least $24 \mathrm{~h}$, then washed with sodium phosphate buffer and dehydrated in a graded ethanol series. Samples were critical-point dried, sputter-coated with gold and visualized with a MERLIN VP Compact microscope (Carl Zeiss, Jena, Germany) at the EMZ of Rostock University Medical Center.

\section{Dot-Blot Overlay}

Plasminogen was immobilized on a nitrocellulose membrane using 1.25, 2.5, 5 and $10.0 \mu \mathrm{g}$ of protein. Unspecific binding sites were blocked by incubation with $10.0 \%$ skimmed milk in PBS supplemented with $0.05 \%$ Tween 20 (PBST) overnight at $4^{\circ} \mathrm{C}$. After 3 washing steps with PBST, the membrane was incubated with $50 \mu \mathrm{g}$ CTHs (in $4 \mathrm{ml} \mathrm{PBST}$ ) overnight at $4^{\circ} \mathrm{C}$. After 3 additional washing steps with PBST, the membrane was incubated with polyclonal histone-specific antibodies from goat (1:500; Antibodies-online, Aachen, Germany) in 1.0\% skimmed milk followed by incubation with horseradish peroxidase-conjugated secondary antibodies $(1: 3,000)$. The antibody detected H1, H2A, H2B, H3 and H4 in similar intensities (data not shown). Visualization of binding signals was performed as described previously [20].

\section{Surface Plasmon Resonance}

The interactions between plasminogen (as an analyte) and histones (as a ligand) were analyzed with a Biacore 3000 system (Biosensor, La Jolla, Calif., USA) using CM3 sensor chips at $25^{\circ} \mathrm{C}$ in PBS as running buffer. Briefly, each histone was immobilized on a flow-cell surface of the chip to densities from 890-1,200 response units using standard amine-coupling chemistry and the software tool 'Application Wizard-Surface Preparation' (Biacore 3000 instrument handbook). Each analyte-ligand complex was allowed to associate and dissociate for 2 and $5 \mathrm{~min}$, respectively, with background subtraction using a flow cell that was subjected to the coupling reaction but without protein, as a reference surface. For con-

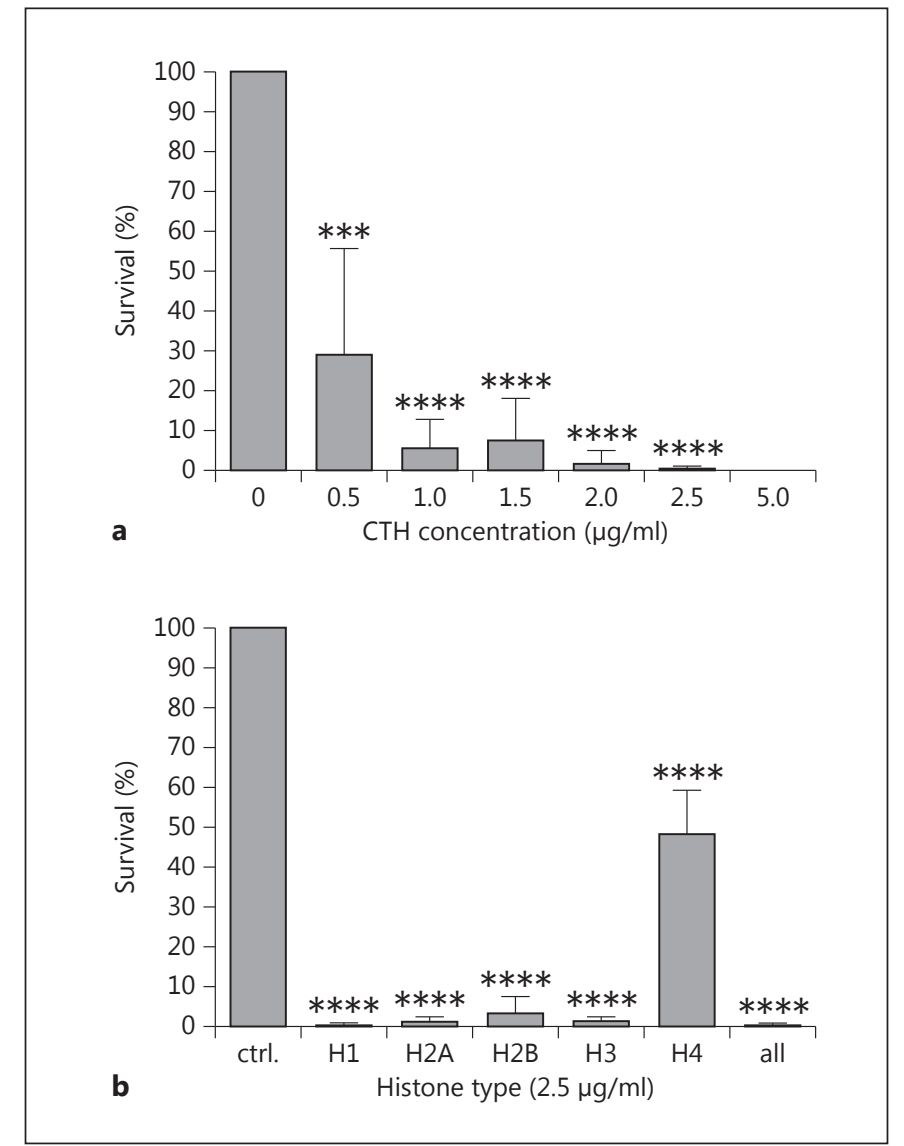

Fig. 1. S. pyogenes M49 is killed by all classes of histones. Exponentially growing $S$. pyogenes M49 bacteria were incubated with CTH at different concentrations (a) or single recombinant histone types at final concentrations of $2.5 \mu \mathrm{g} / \mathrm{ml}$ (b) for $2 \mathrm{~h}$ at $37^{\circ} \mathrm{C}$. Serial dilutions of the samples were plated on THY agar plates to determine CFU after incubation overnight. Survival was calculated by equating buffer-incubated bacteria with $100 \%$. $\mathrm{n} \geq 4$. ${ }^{* * *} \mathrm{p}<0.001$, **** $\mathrm{p}<0.0001$.

centration series, plasminogen was tested at 25,50,100, 200 or $400 \mathrm{nM}$. The ligand surface was regenerated with a 15 -second injection of $0.2 \%$ SDS at the end of each binding cycle. The data from the Biacore sensorgrams were fitted globally, using the 1-step biomolecular association reaction model (1:1 Langmuir binding with drifting base line).

\section{Results}

\section{S. pyogenes M49 Strain Is Killed by All Classes of}

Histones

Compared to other antimicrobial peptides, histones kill bacteria at very low concentrations. In a first experiment, we examined the susceptibility of the S. pyogenes 


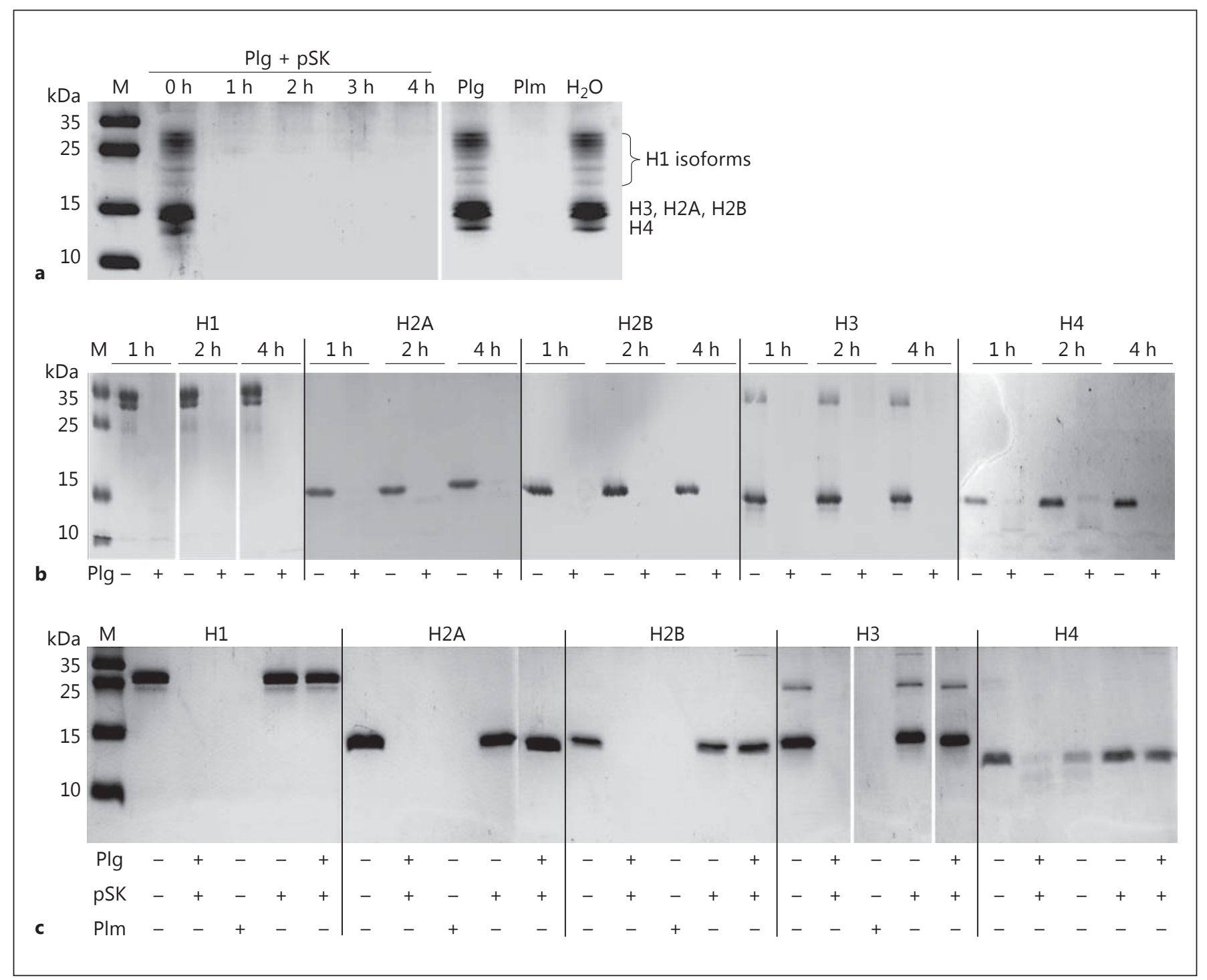

Fig. 2. Plasminogen activation by streptokinase triggers the degradation of all histone subtypes; $10 \mu \mathrm{g}$ histones from calf thymus (a) or single recombinant histones $(\mathbf{b}, \mathbf{c})$ were incubated with $50 \mathrm{U}$ purified streptokinase (pSK) and $1 \mu \mathrm{g}$ plasminogen $(\mathrm{Plg})$ at $37^{\circ} \mathrm{C}$.
Incubation occurred for $4 \mathrm{~h}(\mathbf{a}, \mathbf{c})$ or $1-4 \mathrm{~h}(\mathbf{b})$ and the histones were then subjected to SDS-PAGE and Coomassie gel staining. Histones incubated with Tris buffer or plasmin (Plm) served as negative or positive controls, respectively.
M49 serotype strain to mixed histones from calf thymus. Exponentially growing bacteria were incubated with $\mathrm{CTH}$ at different concentrations, ranging from 0.5 to 5.0 $\mu \mathrm{g} / \mathrm{ml}$ (fig. 1a). Survival of S. pyogenes M49 increased as the concentration of histones decreased. With $0.5 \mu \mathrm{g} / \mathrm{ml}$ $\mathrm{CTH}$, the number of surviving bacteria was significantly decreased. All bacteria were killed at $5.0 \mu \mathrm{g} / \mathrm{ml}$ (fig. 1a). Next, we distinguished between the 5 histone subtypes $\mathrm{H} 1, \mathrm{H} 2 \mathrm{~A}, \mathrm{H} 2 \mathrm{~B}, \mathrm{H} 3$ and H4, and tested their bactericidal activity against $S$. pyogenes M49 individually (fig. 1b). Us- ing histone concentrations of $2.5 \mu \mathrm{g} / \mathrm{ml}$ (corresponding to $0.12,0.18,0.18,0.16$ and $0.22 \mu \mathrm{M}$ for $\mathrm{H} 1, \mathrm{H} 2 \mathrm{~A}, \mathrm{H} 2 \mathrm{~B}$, $\mathrm{H} 3$ and $\mathrm{H} 4$, respectively), all subtypes decreased the survival rate of the tested strain significantly. Histones $\mathrm{H} 1$, $\mathrm{H} 2 \mathrm{~A}, \mathrm{H} 2 \mathrm{~B}$ and $\mathrm{H} 3$ killed $>90 \%$ of the bacteria and histone $\mathrm{H} 4$ killed around 50\% (fig. 1b). Taken together, our results show that intact histones are potent bactericidal proteins that kill S. pyogenes M49 at concentrations in the nanomolar range. 
Fig. 3. Plasminogen activation by streptokinase triggers degradation of nucleosomes. Nucleosomes $(3.2 \mu \mathrm{g})$ were incubated with Tris buffer (ctrl.), plasmin (Plm, $0.3 \mu \mathrm{g}$ ) or purified streptokinase (pSK, $16.6 \mathrm{U})$ and plasminogen (Plg, $0.3 \mu \mathrm{g})$ at $37^{\circ} \mathrm{C}$ for 4 or $16 \mathrm{~h}$. a SDS-PAGE and Coomassie gel staining of the samples. b Agarose gel and ethidium-bromide staining of the samples.

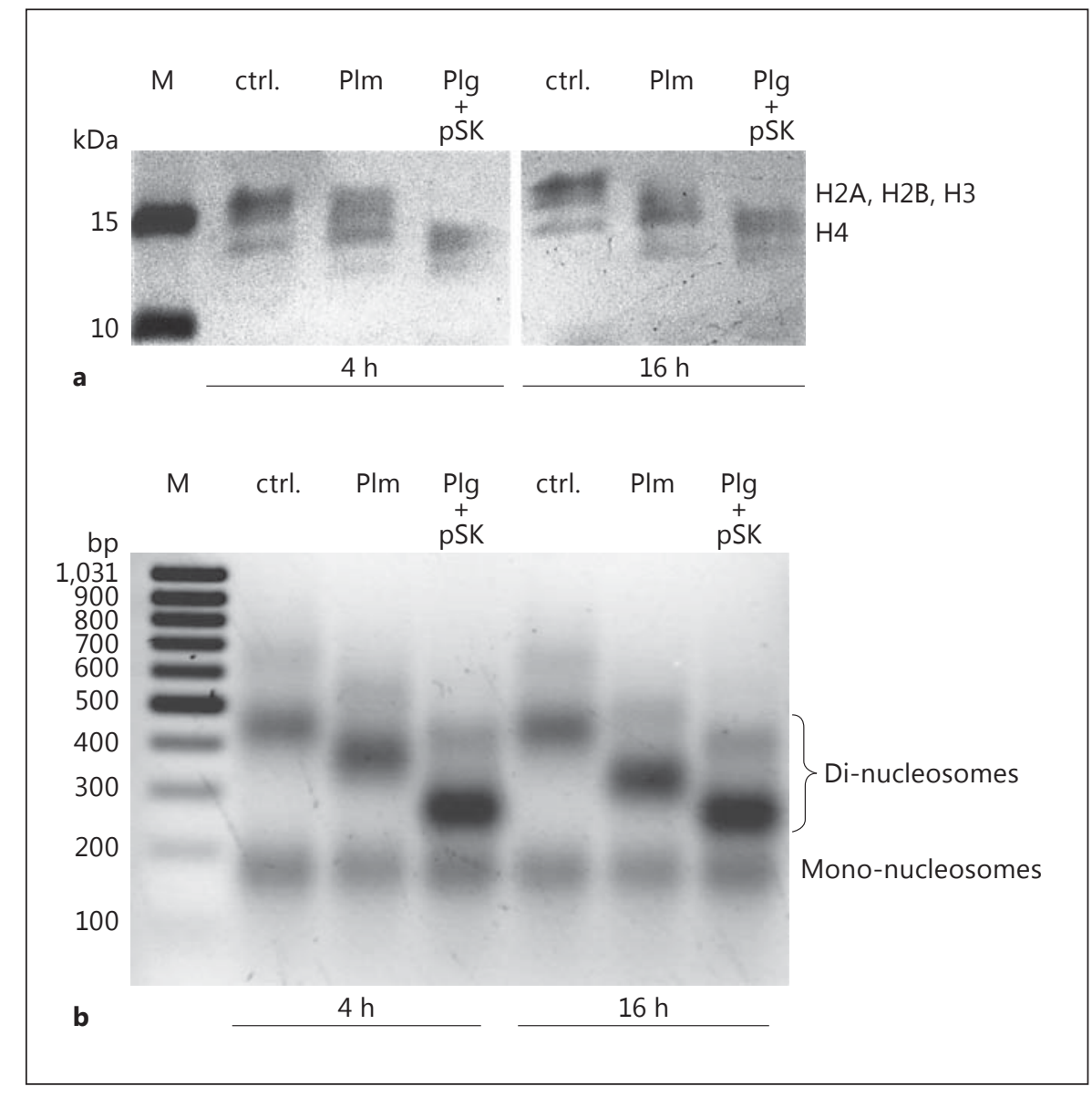

\section{Plasminogen Activation by Streptokinase Triggers}

Degradation of Free Histones

It has been shown previously that $\mathrm{CTH}$ are cleaved by plasmin [15]. It is also well known that $S$. pyogenes expresses the plasminogen activator streptokinase, and exploits human plasmin activity that is a critical host pathogenicity factor for S. pyogenes infection [14]. This prompted us to investigate whether this mechanism might contribute to the streptococcal defense strategy against extracellular histones. Streptokinase and plasminogen were incubated with CTH and samples were analyzed by SDS-PAGE (fig. 2). Already after $1 \mathrm{~h}$, CTH were completely degraded by streptokinase and plasminogen, but not by plasminogen alone (fig. 2a). Repeating the experiment with each individual histone subtype revealed that all histone subtypes were degraded by plasminogen and streptokinase within $4 \mathrm{~h}$ (fig. 2b). A weak band, representing full-size histone $\mathrm{H} 4$, was still detectable after incubation with plasmin or the streptokinase-plasminogen complex (fig. 2b, c). However, the intensity of this signal was lower than the control, and smaller fragments (cleavage products) became visible. This indicates that the streptokinase-plasminogen complex is able to cleave histone $\mathrm{H} 4$, even though the degradation process seems not as efficient as for the other histone types (fig. 2c). Incubation of histones with plasmin resulted in complete degradation of mixed (fig. 2a) and individual histones $\mathrm{H} 1$, $\mathrm{H} 2 \mathrm{~A}, \mathrm{H} 2 \mathrm{~B}$ and H3 (fig. 2c). Streptokinase or plasminogen alone did not degrade histones (fig. 2c).

\section{Plasminogen Activation by Streptokinase Triggers Degradation of Nucleosomes}

Within the human vasculature, histones circulate as nucleosomes bound to DNA. We therefore tested how susceptible nucleosomes are to plasmin-mediated degradation. When nucleosomes were incubated with plasmin, the bound histones were partially degraded, as detected by SDS-PAGE (fig. 3a) or agarose gel of the nucleosomeDNA (fig. 3b). As depicted in figure $3 \mathrm{~b}$, a downshift of the nucleosome-DNA emerges due to degradation of bound 
Table 1. Affinity constants for the binding of plasminogen to histones

\begin{tabular}{lllll}
\hline Protein & $k_{\mathrm{a}}(1 / \mathrm{Ms})$ & $k_{\mathrm{d}}(1 / \mathrm{s})$ & $K_{\mathrm{A}}(1 / \mathrm{M})$ & $K_{\mathrm{D}}(\mathrm{M})$ \\
\hline Histone H1 & $3.33 \times 10^{2}$ & $1.24 \times 10^{-5}$ & $2.68 \times 10^{7}$ & $3.73 \times 10^{-8}$ \\
Histone H2A & $1.14 \times 10^{4}$ & $5.78 \times 10^{-3}$ & $1.98 \times 10^{6}$ & $5.06 \times 10^{-7}$ \\
Histone H2B & $8.01 \times 10^{3}$ & $5.78 \times 10^{-5}$ & $1.39 \times 10^{6}$ & $7.21 \times 10^{-7}$ \\
Histone H3 & $5.13 \times 10^{4}$ & $7.75 \times 10^{-4}$ & $6.62 \times 10^{7}$ & $1.51 \times 10^{-8}$ \\
Histone H4 & $4.98 \times 10^{3}$ & $7.88 \times 10^{-5}$ & $6.32 \times 10^{7}$ & $1.58 \times 10^{-8}$ \\
\hline
\end{tabular}

histones (fig. 3b). When nucleosomes were incubated with plasminogen and streptokinase, the degradation of histones was markedly pronounced (fig. 3a), which is also visible by a clear downshift of the nucleosome-DNA (fig. 3b). Thus, the streptokinase-plasminogen complex is very potent in the degradation of free histones as well as histones bound in nucleosomes.

\section{Plasminogen Binds to All Subclasses of Histones}

It has been shown that some main plasma proteins, such as albumin or fibrinogen, are bound and precipitated by histones [21], and the globular $\mathrm{C} 1 \mathrm{q}$ receptor $\mathrm{p} 33$ has been shown to bind all classes of histones with high affinity [22]. Further on, H2B has been described as an extracellular plasminogen receptor [23]. Thus, we also performed dot-blot overlay analysis (online suppl. fig. 1a; see www.karger.com/doi/10.1159/000448039 for all online suppl. material) and surface plasmon resonance experiments to show that plasminogen binds to all subclasses of histones (online suppl. fig. 1b-f) with high-affinity constants (table 1). Histones $\mathrm{H} 1, \mathrm{H} 3$ and $\mathrm{H} 4$ have the strongest affinity to plasminogen with $\mathrm{K}_{\mathrm{D}}$ values in the nanomolar range (table 1 ).

\section{Plasminogen Activation Is Essential for Histone}

\section{Degradation by Streptococcal Supernatants}

Since S. pyogenes secretes streptokinase into the environment, we investigated the capability of streptococcal culture supernatants from S. pyogenes M49 WT and its $\Delta s k a$ strain to degrade CTH in the presence of human plasminogen. SDS-PAGE analyses revealed complete degradation of CTH incubated with culture supernatant from WT and plasminogen within $4 \mathrm{~h}$ (fig. 4a). In addition, $\Delta s k a$ supernatant together with plasminogen degraded CTH within $4 \mathrm{~h}$, but larger cleavage products were still detectable (fig. 4a). Plasminogen is essential for $\mathrm{CTH}$ cleavage by streptococcal culture supernatants because in the absence of this factor, CTH remained intact (fig. 4a).
Moreover, activation to plasmin is necessary for the degradation process (fig. 2a). Degradation of histones in $\Delta s k a$ supernatant is slow and incomplete after $4 \mathrm{~h}$ (fig. $4 \mathrm{~b}$ ), compared to the WT where a complete breakdown of the histones occurs within $1 \mathrm{~h}$ (fig. $4 \mathrm{~b}$ ). Interestingly, it was recently shown that in the absence of streptokinase, the host plasminogen activator uPA promotes cell surface plasmin acquisition by GAS and facilitates widespread systemic infection [24]. When the host plasminogen activators $\mathrm{uPa}$ or $\mathrm{tPA}$ were added to the $\Delta$ ska supernatant, a rapid degradation of histones was detectable (fig. 4b), suggesting a conversion of plasminogen to proteolytically active plasmin by exploitation of the host-derived uPA and tPA.

When a plasmin-specific inhibitor was added to the samples, CTH degradation by $\Delta s k a$ supernatant was prevented (fig. 4c). We therefore concluded that $\Delta s k a$ supernatant generates small amounts of plasmin from its precursor, although lacking the plasminogen activator streptokinase and failing to induce plasmin activity measured by a substrate assay $[18,25]$. As the plasmin inhibitor cannot interfere with the streptokinase-plasminogen/plasmin complex [26], WT supernatant led to an efficient plasminogen-dependent degradation of $\mathrm{CTH}$, even in the presence of the inhibitor (fig. 4c). In addition, singlechain plasminogen - detected as a signal at $92 \mathrm{kDa}$ in SDS gels - was depleted by WT supernatant but not by $\Delta s k a$ supernatant or medium, nor by supernatants supplemented with the plasmin inhibitor (fig. 4c). According to these results, we conclude that the generation of plasmin by streptokinase is an important factor for histone degradation by $S$. pyogenes culture supernatants.

Plasmin-Degraded Histones Lose Their Antimicrobial and Hemolytic Activity

Next, we investigated whether plasmin-degraded histones still exhibit antimicrobial activity against $S$. pyogenes. CTH or histone subtypes were preincubated with plasmin or buffer for $4 \mathrm{~h}$ and subsequently added to exponentially growing $S$. pyogenes M49 bacteria. Bacterial counts revealed that plasmin-degraded histones lost their antimicrobial activity (fig. 5a). As shown before, almost all bacteria were killed when they were treated with $\mathrm{CTH}$, while the survival rate increased to $92 \%$ when the CTH were pretreated with plasmin. Plasmin alone had no effect on bacterial survival (fig. 5a). Preincubation of the single histone types $\mathrm{H} 1, \mathrm{H} 2 \mathrm{~A}, \mathrm{H} 2 \mathrm{~B}$ and $\mathrm{H} 3$ with plasmin also destroyed their bactericidal properties (fig. 5b). H4 could not be completely degraded by plasmin (see fig. $2 \mathrm{~b}$ ) and so preincubation of $\mathrm{H} 4$ with plas- 


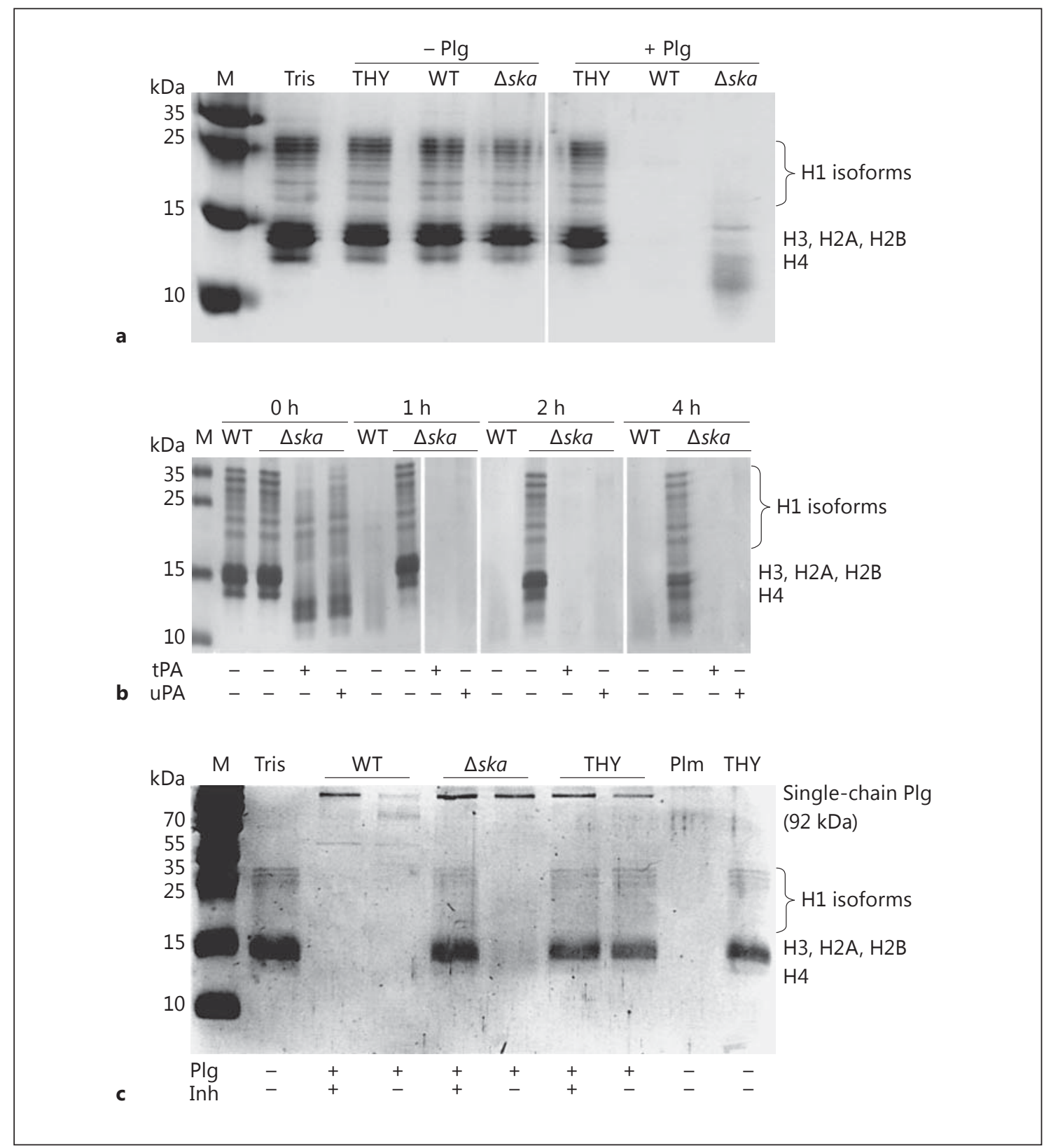

Fig. 4. Plasminogen is essential for histone degradation by streptococcal supernatant. Supernatants from streptococcal overnight cultures in THY medium were added to histones from calf thymus (10 $\mu \mathrm{g}$ in $10 \mathrm{mM}$ Tris buffer) and incubated at $37^{\circ} \mathrm{C}$ for $4 \mathrm{~h}$, if not otherwise indicated. Subsequently, the samples were subjected to SDS-PAGE and Coomassie gel staining. a Supernatants from M49 WT and isogenic mutant strain, lacking the $\Delta s k a$, were tested. His-

min did not influence bacterial survival rates significantly positively (fig. 5b). In some experiments with plasmin-degraded histones, the survival rate exceeded $100 \%$ (fig. 5b). This might be explained by the fact that

S. pyogenes Defends against Histones tones plus THY medium or Tris buffer served as negative controls. Plasminogen was added to indicated samples (+ Plg). b Supernatants from WT or $\Delta s k a$ were incubated with CTH and plasminogen. tPA or uPA were added to indicated samples, and incubated for 1-4 h. c A plasmin inhibitor (Inh) was added to the supernatants of WT and $\Delta s k a$ mutant prior to histone incubation over $4 \mathrm{~h}$. Inhibitor-free samples served as controls. histone fragments and derived amino acids could serve as nutrient source. These data show that plasmin activity is apparently able to render histones harmless to S. pyogenes. 

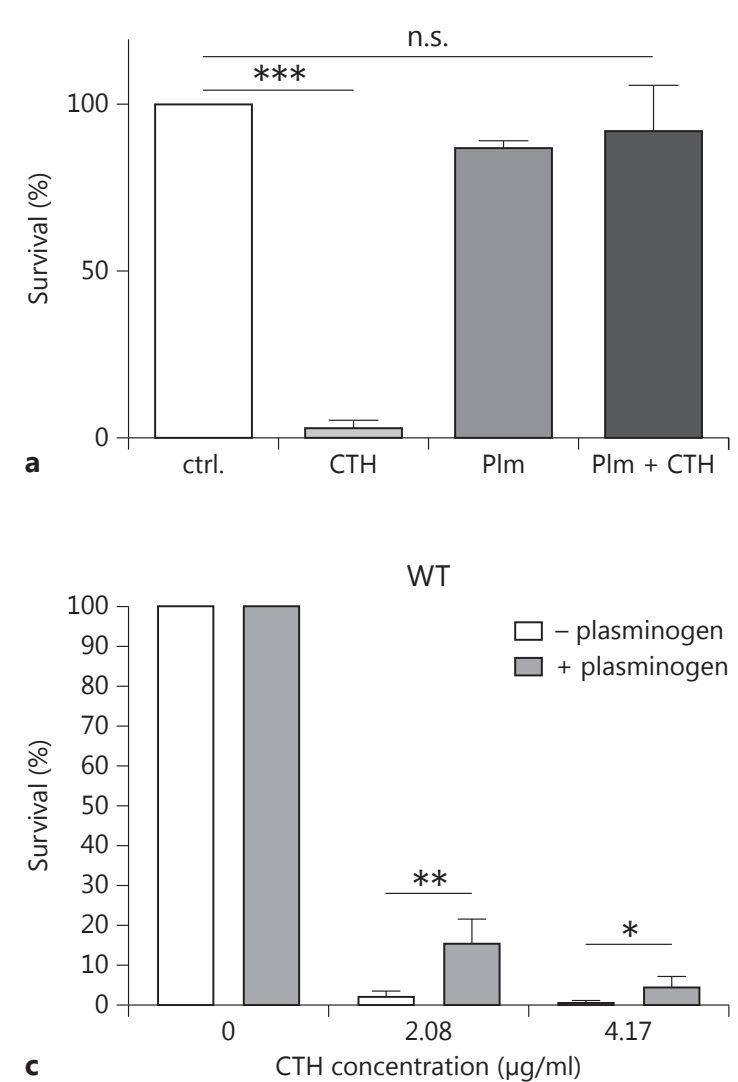

Fig. 5. Histone-killing is diminished by degradation with plasmin or plasminogen binding to S. pyogenes M49. Histones $(10 \mu \mathrm{g})$ from the calf thymus $(\mathbf{a}, \mathrm{n}=3)$ or single recombinant histones $(\mathbf{b}, \mathrm{n}=4)$ were degraded by plasmin $(1 \mu \mathrm{g})$ at $37^{\circ} \mathrm{C}$ for $4 \mathrm{~h}$, diluted by factor 20 , and subsequently tested for antimicrobial activity against $S$. pyogenes M49 from the exponential growth phase. Bacteria were incubated with plasmin-treated histones $(\mathrm{Plm}+\mathrm{CTH})$ for $2 \mathrm{~h}$ at $37^{\circ} \mathrm{C}$. Incubation with non-treated histones (CTH) served as killing control, whereas bacteria incubated in Tris buffer (ctrl.) served as survival control (100\%). Growth inhibition by Plm could be

Extracellular histones are cytotoxic against eukaryotic cells and exert hemolytic activity against human eythrocytes [27]. In the next experiment, we tested whether plasmin could prevent histone-induced hemolysis. Compared to the positive control (100\% hemolysis), CTH at concentration of $100 \mu \mathrm{g} / \mathrm{ml}$ induced $25 \%( \pm 13.9, \mathrm{n}=4)$ hemolysis of erythrocytes. Preincubation of histones with plasmin completely prevented hemolysis, as no absorbance at $540 \mathrm{~nm}$ was detected ( $0 \%$ hemolysis). Taken together, the data show that plasmin-induced degradation of histones very efficiently prevents the hemolytic effect of histones.
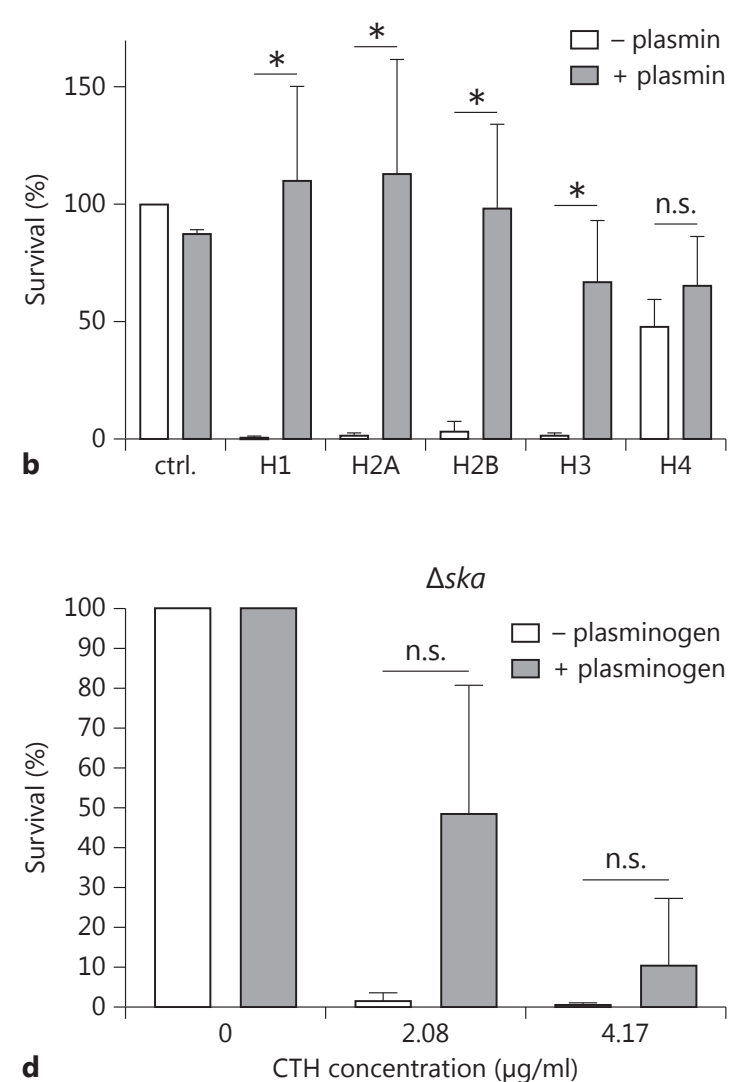

excluded. S. pyogenes M49 WT (c) and isogenic $\Delta$ ska mutant strain from exponential growth phase (d) were preincubated with plasminogen at $200 \mu \mathrm{g} / \mathrm{ml}$ final concentration (black bars) or equal volumes of Tris buffer (white bars) for $15 \mathrm{~min}$ at room temperature. Thereafter, bacteria were washed and $\mathrm{CTH}$ were added to different concentrations. After incubation $\left(2 \mathrm{~h}\right.$ at $\left.37^{\circ} \mathrm{C}\right)$, bacterial counts were determined and referred to results obtained with bacteria incubated in Tris buffer. ${ }^{*} \mathrm{p}<0.05,{ }^{* *} \mathrm{p}<0.01,{ }^{* * *} \mathrm{p}<0.001$. n. s. = Not significant.

\section{Addition of Plasminogen to S. pyogenes M49 Diminishes Histone-Mediated Killing}

Next, we examined whether the addition of plasminogen could protect $S$. pyogenes against histone-induced killing. For this, we incubated WT bacteria with human plasminogen at a concentration found in human plasma $(200 \mu \mathrm{g} / \mathrm{ml})$, and tested whether this approach diminishes the killing effect of histones. Indeed, the survival rates of the WT increased significantly when bacteria were allowed to bind plasminogen and were subsequently exposed to CTH (fig. 5c). As described above, S. pyogenes exploits human plasminogen by activating it through its 

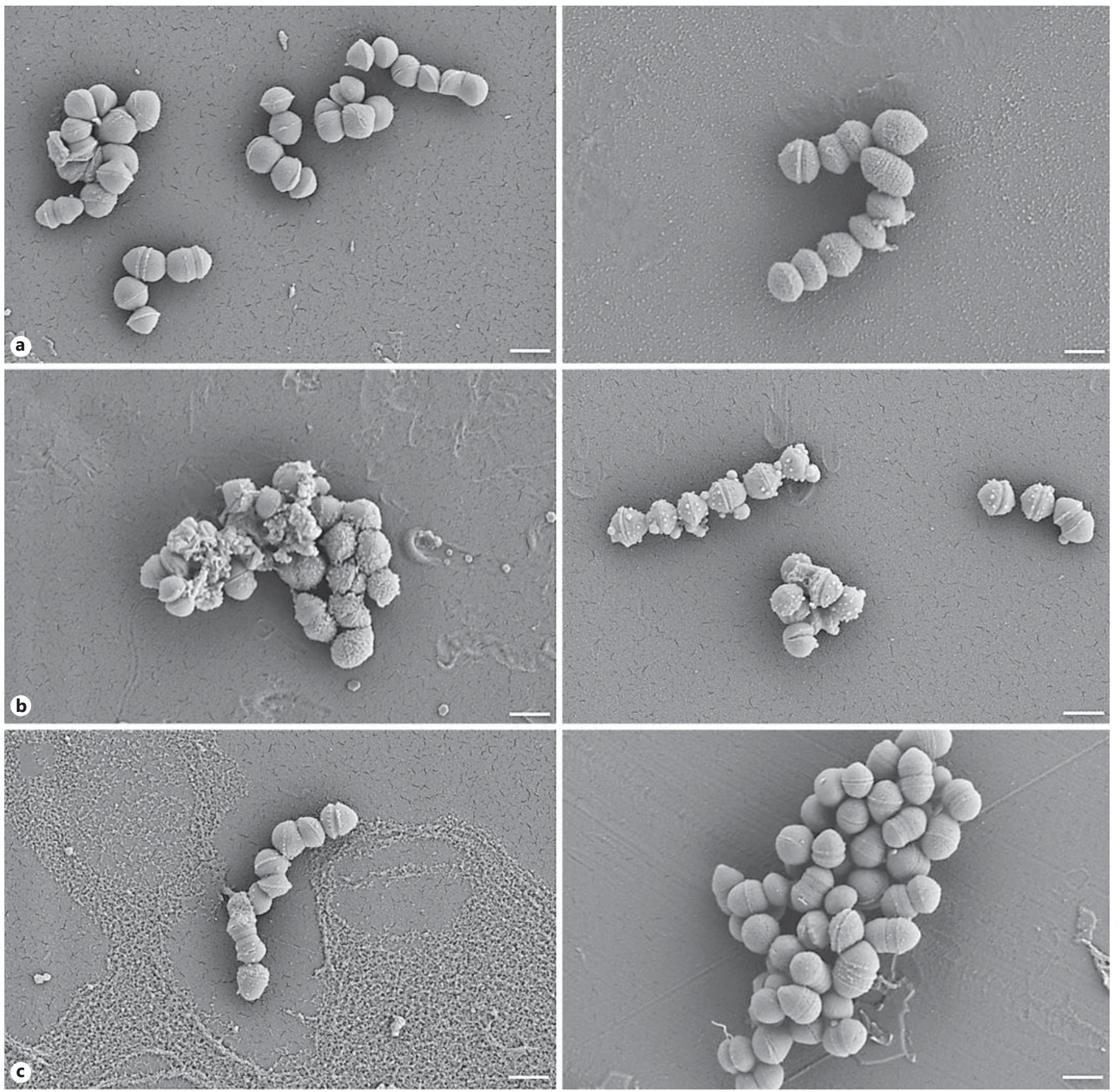

Fig. 6. Killing of S. pyogenes M49 bacteria by histones is prevented after addition of plasminogen. Scanning electron micrographs from S. pyogenes M49 WT and $\Delta$ ska mutant incubated in Tris buffer supplemented with plasminogen (a) or killed by $0.5 \mu \mathrm{g} / \mathrm{ml}$ histones from calf thymus (b). c Addition of plasminogen $(200 \mu \mathrm{g} / \mathrm{ml})$ to bacteria, and subsequent histone treatment. Scale bars: $1 \mu \mathrm{m}$. 


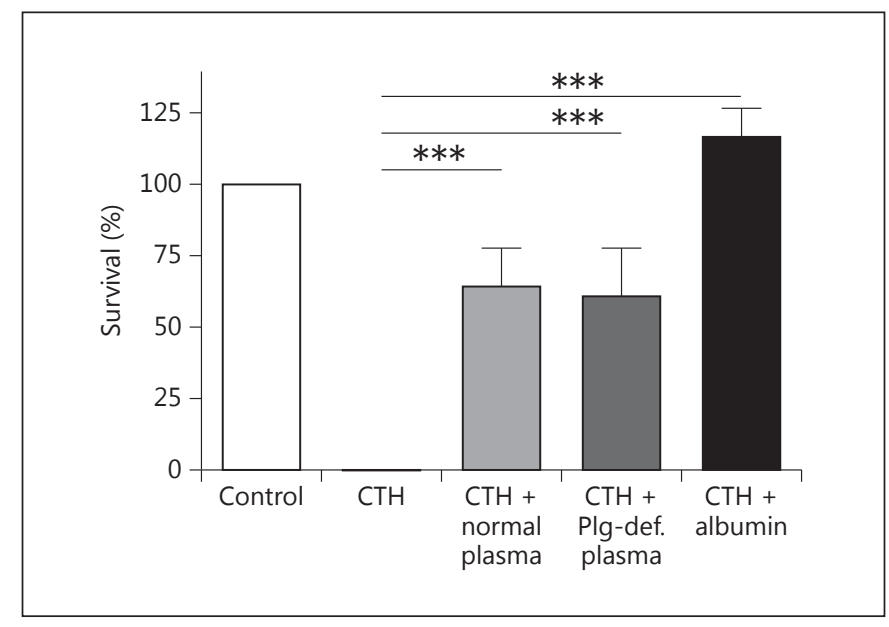

Fig. 7. Incubation of bacteria with human plasma or albumin improves bacterial survival for histones. Human normal or plasminogen-deficient (Plg-def.) plasma (20\%, v/v), or albumin (35 mg/ $\mathrm{ml}$ ) was added to S. pyogenes M49 WT. After incubation, unbound plasma proteins were removed and $\mathrm{CTH}$ added to a final concentration of $5 \mu \mathrm{g} / \mathrm{ml}$. As a control, bacteria were incubated in $10 \mathrm{mM}$ Tris buffer only (control 100\%) or in Tris buffer and CTH. $\mathrm{n}=4$. $* * * \mathrm{p}<0.001$.

virulence factor streptokinase. We considered whether plasminogen was also beneficial for the histone-treated $\Delta s k a$ mutant. The results indicate that the presence of plasminogen also protects $\Delta s k a$ mutant bacteria against CTH killing, even though the data have high standard deviations and differences are not statistically significant in contrast to the WT (fig. $5 \mathrm{~d}$ ). Since the $\Delta s k a$ mutant is not impaired in its ability to bind plasminogen [18], it could be speculated that binding alone has a protecting effect against killing by histones. As we assume that small amounts of plasminogen become activated by $\Delta s k a$ mutant bacteria, plasmin activity was blocked by the specific plasmin inhibitor before the addition of histones. This treatment did not improve histone-induced killing of the $\Delta s k a$ bacteria (data not shown), but it supports the assumption that plasminogen-binding itself has some protecting effect against histones.

Scanning electron microscopy was performed to visualize CTH-killed bacteria. Figure 6a shows intact bacteria, which were incubated in buffer containing plasminogen. Figure $6 \mathrm{~b}$ depicts that treatment with $\mathrm{CTH}$ caused a killing of the WT and the $\Delta s k a$ mutant, as visualized by a disturbed bacterial cell wall and the efflux of cytosolic components. In contrast, if plasminogen was added before $\mathrm{CTH}$ incubation, the bacteria remained practically unaffected (fig. 6c). Taken together, our findings clearly show that the presence of plasminogen is beneficial for S. pyogenes, diminishing the bactericidal activity of extracellular histones.

\section{Addition of Plasma or Human Albumin Protects against Histone-Mediated Killing}

As plasminogen protects $S$. pyogenes against histones, we tested whether the addition of plasma or human albumin has the same effect. Bacteria from the exponential growth phase were exposed to buffer supplemented with $20 \%$ human normal plasma, plasminogen-depleted plasma or human albumin. After removing unbound proteins, CTH were added to a final concentration of $5 \mu \mathrm{g} /$ $\mathrm{ml}$. Adding either human plasma or albumin improved survival significantly (fig. 7). Again, bacterial counts from killing were related to control samples with and without plasma, in order to cover a possible effect on proliferation. Comparing plasminogen-deficient with normal human plasma, no differences were observed. Thus, other plasma components such as albumin also protect $S$. pyogenes against antimicrobial histones.

\section{Discussion}

The role of extracellular histones in an innate immune mechanism has recently been supported by several studies, especially dealing with their function in NETs. However, extracellular histones are not only abundant in NETs. Certain types have been isolated from the skin or mucous membranes, i.e. the first barriers that pathogenic bacteria encounter during pathogenesis $[8,28,29]$. It was recently shown that the local release of extracellular histones triggers the recruitment of immune cells to the site of infection [30]. Moreover, histones exert antimicrobial activity against many microbes and at very low concentrations, compared to other cationic antimicrobial peptides $[4,31$, 32]. This could be confirmed in our study by testing the susceptibility of the S. pyogenes M49 strain against CTH. $\mathrm{CTH}$ contain the core histones $\mathrm{H} 2 \mathrm{~A}, \mathrm{H} 2 \mathrm{~B}, \mathrm{H} 3, \mathrm{H} 4$ and subtypes of the linker histone $\mathrm{H} 1$. We found that all histone types at final concentrations of $2.5 \mu \mathrm{g} / \mathrm{ml}$, except histone $\mathrm{H} 4$, revealed equal potency as antimicrobial agents against S. pyogenes M49. Similar concentrations of histone $\mathrm{H} 2 \mathrm{~A}$ have been previously demonstrated to significantly kill Staphylococcus aureus [5]. Of note, a 10-fold concentration of recombinant histone $\mathrm{H} 4$ was needed to induce a significant killing of $S$. aureus strain in another study [8]. This underlines our observation that histone $\mathrm{H} 4$ killed only around $50 \%$ of the streptococci in our assays, com- 
pared to nearly $100 \%$ killing rates achieved with the other histone types. Since S. pyogenes expresses a set of plasminogen receptors [33], the recruitment of the zymogen to the bacterial surface might be an actual strategy by the receptors to protect themselves from killing by bactericidal histones. Interestingly, our M49 strain and the GAS strains, which are associated primarily with skin infections, bind plasminogen directly and with high affinity $[18,34]$. It has been suggested that the plasminogen-binding capacity may be important for the persistence of such GAS strains in skin infection [35]. Indeed, we could show that M49 survival from histone treatment was increased when bacteria were preincubated with plasminogen. However, plasma provides a number of other proteins that were identified as interacting with extracellular histones, implicating cytoprotection [21]. It was not only plasminogen that protects the streptococci from killing by histones, as the preincubation with plasminogen-deficient plasma also diminished the bactericidal activity of histones. Since S. pyogenes binds various plasma proteins such as albumin or fibrinogen [36], this result was not unexpected. In 1958, Hirsch [4] could not observe a significant growth inhibition of bacteria when he incubated a strain of GAS with $25 \mu \mathrm{g} / \mathrm{ml}$ of the arginine-rich fraction of $\mathrm{CTH}$; the buffer system used was supplemented with albumin. This abundant plasma protein was recently shown to bind extracellular histones, thereby inhibiting histone-induced platelet aggregation [37]. Here, we show that physiological concentrations of albumin also abolish the antimicrobial effects of histones in our assay. This supports earlier findings, showing that the bacteria are no longer dependent on human plasminogen function for virulence, when they have entered the bloodstream [14]. Thus, activation of plasminogen by GAS at the site of infection may be an important strategy to defend histone killing.

Some time ago, it was described by Harvima et al. [15] that the active serine protease plasmin is able to degrade histones. Plasmin in complex with streptokinase cannot be blocked by naturally occurring inhibitors [26], and thus considerable protease activity can be created very rapidly. In fact, we could confirm that not only plasmin but also streptokinase-activated plasminogen leads to an efficient degradation of all histone subtypes in vitro. Moreover, the degradation of histones that are bound in nucleosomes was more pronounced by streptokinase/ plasminogen than by plasmin, supporting the rapid and unresisted protease activity of the plasminogen-streptokinase complex. We found that the resulting cleavage products of the formerly bactericidal histones did not kill S. pyogenes M49 any longer. In this context, completely

S. pyogenes Defends against Histones degraded histones might provide an additional nutrient source for the bacteria. Although $\mathrm{H} 4$ bound plasminogen with high affinity, it was not completely degraded by plasmin or the streptokinase/plasminogen complex within $4 \mathrm{~h}$. Both intact as well as fragmented histone $\mathrm{H} 4 \mathrm{might}$ be responsible for the observed antibacterial activity against the pathogen. Beyond that, $\mathrm{CTH}$ were rapidly degraded by culture supernatants from the streptokinaseproducing WT strain, if plasminogen was present. Surprisingly, supernatants from $\Delta s k a$ also induced histone degradation in the presence of plasminogen, but, compared to the WT, such degradation was slow and incomplete. In addition to surface-located plasminogen receptors, GAS bacteria secrete the glycolytic pathway enzymes, $\alpha$-enolase [38] and GAPDH/Plr/SDH [39] which display plasminogen-binding abilities. No plasmin activity can be detected after the binding of GAS $\alpha$-enolase to plasminogen by a substrate assay [38]. However, for us, it is conceivable that plasminogen-binding by enolase or other GAS proteins [40] may promote a weak activation of plasminogen that is not detectable by a substrate-assay, but is visible by histone degradation. At this point, we exclude an autoactivation of plasminogen, as there is no degradation of histones detectable if they were incubated with plasminogen in the absence of bacterial proteins (see fig. 4a). Thus, secreted GAS-proteins that bind to plasminogen may be responsible for low plasmin activity.

Our experiments show that the degradation of extracellular histones by surface-bound plasmin or complexes of secreted streptokinase and plasmin(ogen) likely contribute to the evasion of $S$. pyogenes from this host innate immune mechanism. This assumption is underlined by reports of Hollands et al. [41] and Ly et al. [42], describing that plasminogen acquisition protects $S$. pyogenes from killing by other antimicrobials, such as cathelicidin LL-37 and complement factor C3b.

Taken together, our results proved that neutralization of histones by bacterial plasminogen binding as well as proteolytic degradation by plasmin might be relevant processes to escape from this innate immune mechanism.

\section{Acknowlegdements}

We thank Jana Normann for excellent technical assistance and Dr. Frank from the EMZ of Rostock University Medical Center for excellent assistance with electronmicroscopy. This study was supported by a grant from the Deutsche Forschungsgemeinschaft (project OE 547/2-1 [S.O.-H.]) and by a grant from the Medical Faculty of the University of Rostock in the framework of the FORUN program 2012. 


\section{References}

$>1$ Walker MJ, Barnett TC, McArthur JD, Cole JN, Gillen CM, Henningham A, et al: Disease manifestations and pathogenic mechanisms of group A streptococcus. Clin Microbiol Rev 2014;27:264-301.

-2 Brinkmann V, Zychlinsky A: Neutrophil extracellular traps: is immunity the second function of chromatin? J Cell Biol 2012;198: 773-783.

-3 Felsenfeld G, Groudine M: Controlling the double helix. Nature 2003;421:448-453.

4 Hirsch JG: Bactericidal action of histone. J Exp Med 1958;108:925-944.

$>5$ Brinkmann V, Reichard U, Goosmann C, Fauler B, Uhlemann Y, Weiss DS, et al: Neutrophil extracellular traps kill bacteria. Science 2004;303:1532-1535.

6 Papayannopoulos V, Zychlinsky A: NETs: a new strategy for using old weapons. Trends Immunol 2009;30:513-521.

$>7$ Köckritz-Blickwede von M, Nizet V: Innate immunity turned inside-out: antimicrobial defense by phagocyte extracellular traps. J Mol Med 2009;87:775-783.

$>8$ Lee D-Y, Huang C-M, Nakatsuji T, Thiboutot D, Kang S-A, Monestier M, et al: Histone H4 is a major component of the antimicrobial action of human sebocytes. J Investig Dermatol 2009; 129:2489-2496.

9 LaRock C, Nizet V: Cationic antimicrobial peptide resistance mechanisms of streptococcal pathogens. Biochim Biophys Acta 2015; 1848:3047-3054

10 Wartha F, Beiter K, Normark S: Neutrophil extracellular traps: casting the NET over pathogenesis. Curr Opin Microbiol 2007;10: 52-56.

$>11$ Law RHP, Abu-Ssaydeh D, Whisstock JC: New insights into the structure and function of the plasminogen/plasmin system. Curr Opin Struct Biol 2013;23:836-841.

-12 Walker MJ, McArthur JD, McKay F, Ranson M: Is plasminogen deployed as a Streptococcus pyogenes virulence factor? Trends Microbiol 2005;13:308-313.

$>13$ McKay FC, McArthur JD, Sanderson-Smith ML, Gardam S, Currie BJ, Sriprakash KS, et al: Plasminogen binding by group A streptococcal isolates from a region of hyperendemicity for streptococcal skin infection and a high incidence of invasive infection. Infect Immun 2004;72:364-370.

-14 Sun H, Ringdahl U, Homeister JW, Fay WP, Engleberg NC, Yang AY, et al: Plasminogen is a critical host pathogenicity factor for group A streptococcal infection. Science 2004;305: 1283-1286.

15 Harvima RJ, Yabe K, Fräki JE, Fukuyama K, Epstein WL: Hydrolysis of histones by proteinases. Biochem J 1988;250:859-864.

16 Pavia K, Spinella S, Elmore D: Novel histonederived antimicrobial peptides use different antimicrobial mechanisms. Biochim Biophys Acta 2012;1818:869-876.
17 Morita S, Tagai C, Shiraishi T, Miyaji K, Iwamuro S: Differential mode of antimicrobial actions of arginine-rich and lysine-rich histones against Gram-positive Staphylococcus aureus. Peptides 2013;48:75-82.

18 Siemens N, Patenge N, Otto J, Fiedler T, Kreikemeyer B: Streptococcus pyogenes M49 plasminogen/plasmin binding facilitates keratinocyte invasion via integrin-integrinlinked kinase (ILK) pathways and protects from macrophage killing. J Biol Chem 2011; 286:21612-21622.

19 Neville DM: Molecular weight determination of protein-dodecyl sulfate complexes by gel electrophoresis in a discontinuous buffer system. J Biol Chem 1971;246:6328-6334.

20 Oehmcke S, Shannon O, Köckritz-Blickwede von M, Mörgelin M, Linder A, Olin AI, et al: Treatment of invasive streptococcal infection with a peptide derived from human high-molecular weight kininogen. Blood 2009;114: 444-451.

21 Pemberton AD, Brown JK, Inglis NF: Proteomic identification of interactions between histones and plasma proteins: implications for cytoprotection. Proteomics 2010;10: 1484-1493.

22 Westman J, Smeds E, Johansson L, Mörgelin M, Olin AI, Malmström E, et al: Treatment with p33 curtails morbidity and mortality in a histone-induced murine shock model. J Innate Immun 2014;6:819-830.

23 Herren T, Burke TA, Das R, Plow EF: Identification of histone $\mathrm{H} 2 \mathrm{~B}$ as a regulated plasminogen receptor. Biochemistry 2006;45: 9463-9474.

24 Sanderson-Smith ML, Zhang Y, Ly D, Donahue D, Hollands A, Nizet V, et al: A key role for the urokinase plasminogen activator (uPA) in invasive group A streptococcal infection. PLoS Pathog 2013;9:e1003469.

25 Nitzsche R, Rosenheinrich M, Kreikemeyer B, Oehmcke-Hecht S: Streptococcus pyogenes triggers activation of the human contact system by streptokinase. Infect Immun 2015;83: 3035-3042.

26 Cederholm-Williams SA, De Cock F, Lijnen $\mathrm{HR}$, Collen D: Kinetics of the reactions between streptokinase, plasmin and alpha 2-antiplasmin. Eur J Biochem 1979;100:125-132.

27 Westman J, Hansen FC, Olin AI, Mörgelin M, Schmidtchen A, Herwald H: p33 (gC1q receptor) prevents cell damage by blocking the cytolytic activity of antimicrobial peptides. J Immunol 2013;191:5714-5721.

28 Rose FR, Bailey K, Keyte JW, Chan WC, Greenwood D, Mahida YR: Potential role of epithelial cell-derived histone $\mathrm{H} 1$ proteins in innate antimicrobial defense in the human gastrointestinal tract. Infect Immun 1998;66: 3255-3263.

29 Murphy EC, Mohanty T, Frick I-M: FAF and SufA: proteins of Finegoldia magna that modulate the antibacterial activity of histones. J Innate Immun 2014;6:394-404.
30 Westman J, Papareddy P, Dahlgren MW, Chakrakodi B, Norrby-Teglund A, Smeds E, et al: Extracellular histones induce chemokine production in whole blood ex vivo and leukocyte recruitment in vivo. PLoS Pathog 2015; 11:e1005319.

31 Halverson TWR, Wilton M, Poon KKH, Petri $\mathrm{B}$, Lewenza S: DNA is an antimicrobial component of neutrophil extracellular traps. PLoS Pathog 2015;11:e1004593.

32 Gould TJ, Lysov Z, Liaw PC: Extracellular DNA and histones: double-edged swords in immunothrombosis. J Thromb Haemost 2015;13(suppl 1):S82-S91.

-33 Shannon O, Herwald H, Oehmcke S: Modulation of the coagulation system during severe streptococcal disease. Curr Top Microbiol Immunol 2013;368:189-205.

34 Ringdahl U, Sjöbring U: Analysis of plasminogen-binding $\mathrm{M}$ proteins of Streptococcus pyogenes. Methods 2000;21:143-150.

$>35$ Svensson MD, Sjöbring U, Bessen DE: Selective distribution of a high-affinity plasminogen-binding site among group A streptococci associated with impetigo. Infect Immun 1999; 67:3915-3920.

36 Sjöholm K, Karlsson C, Linder A, Malmström $\mathrm{J}$ : A comprehensive analysis of the Streptococcus pyogenes and human plasma protein interaction network. Mol Biosyst 2014;10: 1698-1708.

-37 Lam FW, Cruz MA, Leung H-CE, Parikh KS, Smith CW, Rumbaut RE: Histone induced platelet aggregation is inhibited by normal albumin. Thromb Res 2013;132:69-76.

38 Pancholi V, Fischetti VA: Alpha-enolase, a novel strong plasmin(ogen) binding protein on the surface of pathogenic streptococci. J Biol Chem 1998;273:14503-14515.

39 Pancholi V, Fischetti VA: A major surface protein on group A streptococci is a glyceraldehyde-3-phosphate-dehydrogenase with multiple binding-activity. J Exp Med 1992; 176:415-426.

40 Linke C, Siemens N, Oehmcke S, Radjainia M, Law RHP, Whisstock JC, et al: The extracellular protein factor EPF from Streptococcus pyogenes is a cell surface adhesin that binds to cells through an N-terminal domain containing a carbohydrate-binding module. J Biol Chem 2012;287:38178-38189.

41 Hollands A, Gonzalez D, Leire E, Donald C, Gallo RL, Sanderson-Smith M, et al: A bacterial pathogen co-opts host plasmin to resist killing by cathelicidin antimicrobial peptides. J Biol Chem 2012;287:40891-40897.

42 Ly D, Taylor JM, Tsatsaronis JA, Monteleone MM, Skora AS, Donald CA, et al: Plasmin(ogen) acquisition by group A streptococcus protects against $\mathrm{C} 3 \mathrm{~b}$-mediated neutrophil killing. J Innate Immun 2014;6:240250

Nitzsche/Köhler/Kreikemeyer/

Oehmcke-Hecht 